DOI: $10.17805 /$ trudy.2019.2.8

\title{
ПРИМЕНЕНИЕ ПРОЕКТНОГО МЕНЕДЖМЕНТА В ОРГАНИЗАЦИЯХ ТРАНСПОРТНОЙ ОТРАСЛИ
}

\author{
А. О. Соболева \\ Московский гуманитарный университет
}

\begin{abstract}
Аннотация: В статье рассматривается использование проектного менеджмента в транспортной сфере. Его целью является увеличение эффективности деятельности предприятия с достижением оптимальных экономических результатов.
\end{abstract}

Ключевые слова: проектный менеджмент; транспорт; транспортная отрасль; менеджмент

\section{APPLICATION OF PROJECT MANAGEMENT IN TRANSPORT INDUSTRY ORGANIZATIONS}

\author{
A. O. Soboleva \\ Moscow University for the Humanities
}

Abstract: The paper considers the application of project management in the transport sphere. Its aim is to increase the efficiency of the work of an enterprise leading to optimal economic results.

Keywords: project management; transport; transport industry; management

В нашем обществе, подверженном постоянным переменам, одним из условий обретения значительного успеха в ходе функционирования субъектов предпринимательской инициативы является наличие реальной возможности руководствоваться общими принципами формирования проектного менеджмента, выступающего эффективным инструментом реализации сущности управления.

Объем факторов внешней среды, способствующих возникновению проблемных вопросов в различных сферах хозяйственной деятельности (социокультурной, экологической сфере и др.) и требующих пристального внимания, постоянно расширяется. В связи с этим, разрешение возникших проблем видится во внедрении в практику деятельности прогрессивных по своей сути управленческих решений.

Специфической особенностью проектного управления предстает обширное внедрение многоплановых по технологическим характеристикам 
и предметной сфере проектных решений. При этом существенный акцент делается на аспекты инновационной деловой активности. И возможности управления, в обязательном порядке принимающие в расчет фактор отсутствия достаточного оборотного капитала, а также ориентир на достижение определенной результативности и, несомненно, эксклюзивность используемых решений, приводят к достижению оптимального по своим масштабам (Балашов, Рогова, Тихонова, 2016).

Проектное управление предполагает выполнение особой процедуры управления, состоящей в установлении определенного числа проектов инновационного развития с учетом условий окружающей обстановки и избрании из данного перечня оптимального набора проектов с учетом применения определенного показателя. Указанным показателем выступает обобщенный параметр эффективности функционирования транспортного предприятия в виде индекса увеличения производительности труда. Со своей стороны, сдерживающим параметром предстает уровень обеспеченности конкретного проекта инновационного развития требуемым объемом инвестиционных ресурсов (Каплан, Нортон, 2017).

На протяжении свыше полувека подлежит применению практика внедрения проектного управления. По итогам принятия ряда мер появилось практическое обоснование, подкрепленное соответствующими примерами в рамках уже исполненных решений, что вызвало определенную надобность в проведении действенных мер по систематизации данного процесса, мероприятий по обобщению и обеспечению надлежащей степени унификации.

Положения стандартов в сфере управления проектным менеджментом предстают значимым составляющим элементом формирования единой информационной среды, установления ключевых норм и идейных начал, регулирующих разработку конкретного проекта в целом, его отдельных стадий и этапов при обязательном применении специфики методологических подходов к сущности управления. Указанные обстоятельства предоставляют возможность четко выстраивать проектную деятельность, детально обосновывать и обозначать цели согласно поставленным задачам конкретного предприятия и рассредоточивать имеющийся в распоряжении капитал в условиях его недостаточности, добиваясь оптимального по своей сути результата, необходимого компании (Шапиро, 2014: 247).

Конструкция проектного менеджмента в транспортной сфере состоит в системе формирования, усовершенствования и/или корректировки аспектов деятельности предприятий, как комплекса разного рода проектов для достижения стратегических целевых ориентиров определенного предприятия.

Система проектного управления инновационным развитием транспортной компании должна охватывать процедуры управления всех этапов жиз- 
Научные труды Московского гуманитарного университета 2019 № 2

ненного цикла подвижных единиц, организации аспектов перевозки, управления взаимоотношениями с пользователями и продавцами, управления сферой корпоративной и транспортной безопасности, отношениями в области обеспечения охраны окружающей среды и увеличения эффективности основных видов деятельности (там же: 203). Она предоставляет возможность обозначить стратегические цели предприятия путем разработки стратегической карты, принимающей в расчет главные составляющие элементы управления: объем финансовых средств, партнеров по гражданским договорам, специфику производственных процессов, показатель человеческих ресурсов и, наконец, характерный элемент организационного развития.

В будущие периоды, с учетом отраслевой специфики, формируется система параметров эффективности деятельности предприятия, определяется совокупность конкретных проектов, реализация которых требуется для выполнения стратегических целей предприятия, производится расчет воздействия проекта на показатели эффективности работы предприятия, с учетом инвестиционных перспектив и выполняется избрание оптимального набора проектов на пути инновационного развития (Алексеев, 2017).

Применительно к специфике хозяйственной деятельности транспортной компании процессу управления инновационным развитием присущ ряд специфических этапов, заключающихся в нижеследующем:

1. Обозначение стратегических целей в структуре инновационного развития на базе текущих и прогнозных сведений в рамках избранной компанией стратегии деятельности;

2. Учреждение эффективной системы обеспечения планирования для целей предпринимательской деятельности, обеспечивающей реализацию поставленных перед компанией целей хозяйственной деятельности;

3. Обоснование набора ресурсов, требуемых для реализации предполагаемых проектов, и показателей качества, которые учитывают параметры учета, контроля и мотивации сотрудников;

4. Избрание оптимального варианта инновационного развития и формирования организационной структуры управления инновациями (Табачникова, 2015).

На всех без исключения стадиях управления необходимо четко отслеживать технические новшества в исследуемой отрасли, обеспечивать обязательное внедрение в практику деятельности организации продуктивных технологий, ведущих стандартов и качественных методик работы, применяемых наилучшими предприятиями-аналогами, функционирующими в избранной для анализа отрасли. В свою очередь, целесообразно на постоянной основе рассматривать, выбирать и использовать новые, более совершенные, методики инновационного развития, производить постоянную 
оценку воздействия параметров окружающей обстановки, имеющих наибольший удельный вес для принятия проектов возможных и необходимых решений (Алексашина, 2015: 46).

Следует отметить, что в ходе учреждения надлежащей системы управления проектами инноваций предприятию следует применять целостный подход. Сущность данного подхода состоит в рассмотрении деятельности отдельных служб, отделов, иных структурных подразделений и руководства, напрямую задействованных в данном процессе, как деятельности взаимообусловленной и координированной во всех отношениях. Неэффективная взаимосвязь участников реализации определенного проекта вызывает значительное сокращение темпов претворения в жизнь конкретного проекта, ухудшение параметра качества, приводит к необходимости несения компанией дополнительных трат (Аверин, Григорьевна, 2015).

Субъекты, прибегающие к пользованию всеми возможностями конструкции управления проектами внедрения инноваций, приобретают большую способность к конкуренции в непростых условиях современной рыночной среды по отношению к вертикально объединенным компаниям с их функциональным принципом организации работы (Рагулина, 2017: 4).

Учитывая вышеизложенные обстоятельства, применение всех возможностей проектного управления в транспортной сфере и обеспечение полноценной проработки процессов управления в структуре компании могут в значительной степени оказать помощь в развитии экономических аспектов деятельности предприятия в, несомненно, позитивном ракурсе, отражающем достижение наилучшего для компании финансового результата.

\section{СПИСОК ЛИТЕРАТУРЫ}

Аверин, А. В., Григорьева, В. В. (2015) Внутренний контроль и мониторинг качества консультационных услуг в системе обеспечения эффективности государственной поддержки субъектов малого и среднего предпринимательства // Вестник Университета (Государственный университет управления). № 5. С. 91-95.

Алексашина, Т. В. (2015) Коммерциализация инноваций и перспективы развития сетевых форм поддержки инновационных проектов // Экономические и гуманитарные науки. № 7 (282). С. 43-55.

Алексеев, А. Н. (2017) Инновационная деятельность предприятий промышленности: методология оценки и государственного регулирования // Транспортное дело России. № 6. 159-161.

Балашов, А. И., Рогова, Е. М., Тихонова, М. В. (2016) Управление проектами: учебник для бакалавров. М. : Юрайт. 147 с.

Каплан, Р., Нортон, Д. (2017) Стратегические карты. Трансформация не- 
материальных активов в материальные результаты. М. : ЗАО «Олимп-Бизнес». 512 с.

Рагулина, Ю. В. (2017) Управление интеллектуальным капиталом промышленной организации в условиях экономики знаний. М. : ИЭ РАН.

Табачникова, Е. В. (2015) Влияние модели конкуренции на рыночное поведение грузового автотранспортного предприятия // Вестник СибАДИ. № 1 (41). С. 105-111.

Шапиро, В. Д. (2014) Управление проектами : учебное пособие для студентов. М. : Омега-Л. 852 с.

Дата поступления: 12.03.2019 г.

Соболева Александра Олеговна - студентка магистратуры магистратуры направления «Государственное и муниципальное управление» Московского гуманитарного университета. Адрес: 111395, Россия, г. Москва, ул. Юности, д. 5. Тел.: +7 (910) 449-55-90. Эл. адрес: alekssoboleva@mail.ru

Soboleva Aleksandra Olegovna, Graduate Student, programme of study "State and Municipal Administration", Moscow University for the Humanities. Postal address: 5, Yunosti St., Moscow, Russian Federation, 111395. Tel.: +7 (910) 449-55-90. E-mail: alekssoboleva@mail.ru

\section{Для цитирования:}

Соболева А. О. Применение проектного менеджмента в организациях транспортной отрасли [Электронный ресурс] // Научные труды Московского гуманитарного университета. 2019. № 2. URL: http://journals.mosgu.ru/trudy/article/view/965 (дата обращения: дд.мм.гг.). DOI: 10.17805/trudy.2019.2.8 